\title{
Escherichia coli 0157:H7 in Raw Meat in Addis Ababa, Ethiopia: Prevalence at an Abattoir and Retailers and Antimicrobial Susceptibility
}

\author{
Tizeta Bekele ${ }^{1}$, Girma Zewde ${ }^{1}$, Genene Tefera², Aklilu Feleke ${ }^{1}$ and Kaleab Zerom ${ }^{3 *}$
}

\begin{abstract}
Background: Although raw meat and its products are commonly consumed in traditional Ethiopian diets, E. coli O157: H7 is rarely studied compared to other countries. Thus the present study has been designed to determine the prevalence and assess the antimicrobial susceptibility of $\mathrm{E}$. coli O157: H7 isolated from beef, sheep meat and goat meat at one abattoir and in 48 selected raw meat retail shops in Addis Ababa.
\end{abstract}

Results: Out of 384 meat samples examined, 10.2\% (39/384) were positive to E. coli O157:H7. Among these samples examined, beef was the most frequently contaminated with E. coli O157:H7 with an overall prevalence of 13.3\% $(17 / 128)$ followed by $9.4 \%(12 / 128)$ sheep meat and $7.8 \%$ (10/128) goat meat. With regard to meat source, the prevalence rates of $E$. coli $\mathrm{O} 157: \mathrm{H} 7$ at the abattoir and the selected retail shops were $5.7 \%(11 / 192)$ and $14.6 \%$ (28/192), respectively. Significant differences in prevalence was observed among sample sources $(p<0.05)$. The antimicrobial susceptibility investigation of $39 \mathrm{E}$. coli O157:H7 isolates using 10 commercially available antimicrobial discs revealed that the isolates were susceptible to nine antimicrobials from $69.3 \%$ to $100 \%$ except streptomycin which showed susceptibility of $48.7 \%$. An overall resistance of $33.4 \%$ and $30.9 \%$ was recorded to streptomycin and amikacin, whereas 5.1\%, 5.1\%, 7.7\%, 12.8\% and 17.9\% resistance rates were recorded against nalidixic acid, tetracycline, amoxacilin-clavulanic acid, cephalothin and ciprofloxacin, respectively. Multidrug resistance was observed among amikacin, amoxycillin-clavulanic acid, cephalothin, ciprofloxacin, streptomycin and tetracycline antimicrobials drugs.

Conclusions: The isolation of E. coli $\mathrm{O} 157: \mathrm{H} 7$ in raw meat and the existence of antimicrobial resistant isolates highlight the potential threat to public health. Hence implementation of E. coli O157:H7 prevention and control strategies from farm production to consumption of meat and meat products are crucial.

Keywords: Abattoir; Addis Ababa; Antimicrobials; E. coli O157:H7; Prevalence; Retail shops; Raw meat

\section{Background}

Most Escherichia coli (E. coli) are normal commensals found in the intestinal tract of both humans and animals, while others are pathogenic to humans (CFSPH 2009; Kaper et al. 2004). Pathogenic E. coli distinguished from normal flora by their possession of virulence factors. The specific virulence factors can be used, together with the type of disease, to separate these organisms into pathotypes (CFSPH 2009). E. coli O157: H7 is one of the best known serotype to contain pathotypes that can

\footnotetext{
* Correspondence: kaleabzerom@yahoo.com

${ }^{3}$ College of Veterinary Medicine, Samara University, P.O. Box 132, Samara, Ethiopia

Full list of author information is available at the end of the article
}

cause food borne infection in humans (Acha and Szyfres 2001; IFT 2003). E. coli O157:H7 pathotypes has been found in the intestines of healthy cattle, deer, goats, and sheep (Acha and Szyfres 2001; IFT 2003).

Verocytotoxigenic (or verotoxigenic) E. coli (VTEC) pathotype produces a toxin known as verocytotoxin that is lethal to cultured African green monkey kidney cells (Vero cells) (CFSPH 2009). VTEC may belong to many serotypes, but most severe human infections are caused by $E$. coli O157: H7 serotypes (Mead and Griffin 1998). Enterohemorrhagic E. coli O157: H7 (EHEC) is VTEC that possess additional virulence factors, giving them the ability to cause hemorrhagic colitis and hemolytic uremic syndrome (HUS) in humans. EHEC have been described as important food 
borne pathogens (Vernozy-Rozand 1999). Young children, the elderly, and those with weakened immune systems are the most vulnerable for infection (IFT 2003).

The most frequent mode of transmission for $E$. coli O157:H7 infection to human is through consumption of contaminated food and water. However, it may also spread directly from person to person and occasionally through occupational exposure (Abdalla et al. 2009).

Ruminants, particularly cattle and sheep, are the most important reservoir hosts for EHEC O157:H7 (Cornick et al. 2000). Cattle have been identified as a major reservoir of E. coli O157 (Chapman et al. 2001) and consumption of foods of bovine origin have been associated with some of the largest food poisoning outbreaks in which this organism was identified as the etiologic agent (Meng and Doyle 1998).

The microbiological contamination of carcasses can occur during processing and manipulation, such as skinning, evisceration, storage and distribution at slaughter houses. Fecal matter is a major source of contamination and could reach carcasses through direct deposition, as well as by indirect contact through contaminated equipment, workers, installations and air (Pal 2007). Cattle slaughtering operations, such as bleeding, dressing and evisceration expose sterile muscle to microbiological contaminants that were present on the skin, the digestive tract and in the environment (Bacon et al. 2000; Abdalla et al. 2009).

There are a few reports on the prevalence and antibiotic resistance status of $E$. coli O157: $\mathrm{H} 7$ from raw meat in Ethiopia and little or no studies have been carried out in Addis Ababa. Thus the current study has been designed to determine the prevalence and assess the antimicrobial susceptibility of the microorganism isolated from beef, sheep and goat's meat at one abattoir and in selected meat retail shops in Addis Ababa. The difference between the abattoir included in this study and in the study conducted by Hiko et al. (2008) with respect to the level of establishment (the abattoir included in this study supply meat for local consumption whereas the abattoir in Hiko et al. (2008). study is an export abattoir that fulfill most of international standards), the slaughtering operation and the food safety management system may enable this study to build further on the data provided by Hiko et al. (2008).

\section{Methods}

\section{Study area}

The study was carried out in Addis Ababa, the capital city of the Federal Democratic Republic of Ethiopia.

\section{Description of food business operators included in the study}

The food business operators included in this study, both the abattoir and the selected 48 retail meat shops, do not use any formal food safety management system. The abattoir supplies meat to all of the retailers studied. All of the retail meat shops included in this study does not have any chilling/cooling facilities.

\section{Study design}

A cross-sectional study was conducted to determine the prevalence and assess the antimicrobial susceptibility of E. coli O157: H7 isolated from beef, sheep and goat meat at one abattoir and in 48 selected raw meat retail shops from August 2011 to April 2012 in Addis Ababa.

\section{Study samples}

The study was conducted on a total of 384 raw meat samples consisting of 64 beef, 64 sheep meat and 64 goat meat each collected from one abattoir $(n=192)$ and 48 randomly selected retail shops $(n=192)$ that means with the total of 128 beef, 128 sheep meat and 128 goat meat.

\section{Sampling technique and sample collection procedure}

Swab samples were collected aseptically using systematic random sampling technique from the carcasses of daily slaughtered animals at the abattoir and from legally registered raw meat retailer shops using simple random sampling technique.

Selected carcasses were swabbed using the method described in ISO17604 (2005) by placing sterile template $(10 \times 10 \mathrm{~cm})$ on specific sites of a carcass. A sterile cotton tipped swab, $(2 \times 3 \mathrm{~cm})$ fitted with shaft, was first soaked in an approximately $10 \mathrm{ml}$ of buffered peptone water (Oxoid Ltd., Hampshire, England) rubbed first horizontally and then vertically several times on the carcasses. The abdomen (flank), thorax (lateral) and breast (lateral); which are sites with the highest rate of contamination (ISO 17604, 2005); were chosen for sampling using the same swab over all the sites. On completion of the rubbing process, the shaft was broken by pressing it against the inner wall of the test tube and disposed leaving the cotton swab in the test tube. $25 \mathrm{~g}$ of whole cuts of raw meat sample was collected from retail shops following aseptic techniques. The samples were put in a sterile universal bottle filled with $225 \mathrm{ml}$ of buffered peptone water. Finally, the samples were transported to the Institute of Biodiversity Conservation Laboratory, Addis Ababa using ice box in cold chain for microbiological analysis. Up on arrival, the samples were stored in refrigerator at $4^{\circ} \mathrm{C}$ for $24 \mathrm{hrs}$ until being processed for isolation.

\section{Sample preparation}

Each carcass swabs were homogenized with vortex mixer and $25 \mathrm{~g}$ of raw whole cuts of meat sample collected from each retail shops were taken out from the universal 
bottle, chopped aseptically and the meat was placed with $225 \mathrm{ml}$ of buffered peptone water; from the previous universal bottle; in a plastic bag and homogenized using a homogenizer (Stomacher 400, Seward Medical, England) at high speed for 2 minutes. The resulting suspension was used for isolation of E. coli O157:H7.

\section{Isolation Procedure}

$200 \mu \mathrm{l}$ of prepared sample of a meat rinse solution was streaked onto MacConkey agar (IVD, UK) plates and incubated at $37^{\circ} \mathrm{C}$ for $24 \mathrm{hrs}$. Following incubation, lactose-positive (pink) colonies were streaked onto Sorbitol-MacConkey Agar (IVD, UK) plates and incubated at $37^{\circ} \mathrm{C}$ for $24 \mathrm{hrs}$. The sorbitol negative colorless colonies were sub-cultured on Rainbow agar.

Rainbow Agar O157 (Hayward, USA) was inoculated by spreading a suspected colonies of $E$. coli on its surface. The plates were then incubated for 20 to $24 \mathrm{hrs}$, or longer, at $37^{\circ} \mathrm{C}$ and observed for the presence of colored colonies. The distinctive black or gray coloration of $E$. coli $\mathrm{O} 157$ colonies were easily viewed by laying the Petri dish against a white background. Upon sub-culturing, the isolated E. coli O157 colonies showed their typical black or gray coloration (BiOLOG User Guide 2008). These colonies were tested further using BiOLOG identification system to confirm their identity as E. coli and for any isolate identified as E. coli O157:H7 additional confirmation by serology may be recommended for the reasons of serious implications when this pathogen is determined in a food sample.

\section{Identification}

Pure colonies that showed typical black or gray coloration on Rainbow agar were inoculated on BUG (Biolog Universal Growth Medium) agar (Hayward, USA) with $5 \%$ sheep blood and incubated at $37^{\circ} \mathrm{C}$ for $24 \mathrm{hrs}$. Subculture was made using the same culture media to have pure culture colonies before identification was done by OmniLog. The BUG is a recommended medium for aerobic bacteria and it was employed to isolate E. coli. Following this, the identification of E. coli O157:H7 was performed using the Omnilog plus Identification System (BiOLOG User Guide 2008).

After getting pure culture colonies, identification was carried out using BiOLOG Standard Operation Protocols (SOP). Briefly, bacterial suspension was prepared with an appropriate level of bacterial density, as recommended in the protocol of the instrument. The bacterial suspension was inoculated into the GEN III Micro Plates aseptically. The microplates were covered with lid and incubated at $37^{\circ} \mathrm{C}$ for $22 \mathrm{hrs}$. Then the Micro Plates were loaded into the OmniLog incubator/reader. The bacterial suspension was identified by the instrument using the inbuilt database.

\section{Antimicrobial susceptibility pattern}

The antimicrobial susceptibility test was performed following the standard agar disk diffusion method according to CLSI (2008) using commercially available antimicrobial disks (Table 1).

Table 1. Antibiotic disks used to test E. coli O157:H7 and their respective concentrations.

Each isolated bacterial colony from pure fresh culture was transferred into a test tube of $5 \mathrm{ml}$ Tryptone Soya Broth (TSB) (Oxid, England) and incubated at $37^{\circ} \mathrm{C}$ for 6 hrs. The turbidity of the culture broth was adjusted using sterile saline solution or added more isolated colonies to obtain turbidity usually comparable with that of 0.5 McFarland standards (approximately $3 \times 10^{8} \mathrm{CFU}$ per $\mathrm{ml}$ ). Mueller-Hinton agar (Bacton Dickinson and Company, Cockeysville USA) plates were prepared according to the manufacturer guidelines. A sterile cotton swab was immersed into the suspension and rotated against the side of the tube to remove the excess fluid and then

Table 1 Antibiotic disks used to test $E$. coli 0157:H7 and their respective concentrations

\begin{tabular}{|c|c|c|c|c|c|c|}
\hline \multicolumn{2}{|c|}{ № Antibiotic disks } & \multirow[t]{3}{*}{ Disc code } & \multirow[t]{3}{*}{ Concentration } & \multicolumn{3}{|c|}{ Diameter of zone of inhibition in millimeter $(\mathrm{mm})$} \\
\hline & & & & \multirow{2}{*}{$\begin{array}{l}\text { Resistant } \\
\leq\end{array}$} & \multirow[t]{2}{*}{ Intermediate } & \multirow{2}{*}{$\begin{array}{l}\text { Susceptible } \\
\geq\end{array}$} \\
\hline & & & & & & \\
\hline 1 & Amikacin & AK & $30 \mu \mathrm{g}$ & 14 & $15-16$ & 17 \\
\hline 2 & Amoxycillin-Clavulanic acid & AMC & $20 / 10 \mu g$ & 13 & $14-17$ & 18 \\
\hline 3 & Ceftriaxone & $\mathrm{CRO}$ & $30 \mu \mathrm{g}$ & 14 & $15-17$ & 18 \\
\hline 4 & Cephalothin & KF & $30 \mu \mathrm{g}$ & 14 & $15-17$ & 18 \\
\hline 5 & Chloramphenicol & C & $30 \mu \mathrm{g}$ & 12 & $13-17$ & 18 \\
\hline 6 & Ciprofioxacin & $\mathrm{CIP}$ & $5 \mu \mathrm{g}$ & 15 & $16-20$ & 21 \\
\hline 7 & Nalidixic acid & NA & $30 \mu \mathrm{g}$ & 13 & $14-18$ & 19 \\
\hline 8 & Streptomycin & $\mathrm{S}$ & $10 \mu \mathrm{g}$ & 11 & $12-14$ & 15 \\
\hline 9 & Tetracycline & TE & $30 \mu \mathrm{g}$ & 11 & $12-14$ & 15 \\
\hline 10 & Sulfamethoxazole - Trimethoprim & SXT & $30 \mu \mathrm{g}$ & 10 & $11-15$ & 16 \\
\hline
\end{tabular}


swabbed in three directions uniformly on the surface of Mueller-Hinton agar plates. After the plates dried, antibiotic disks were placed on the inoculated plates using sterile forceps. The antibiotic disks were gently pressed onto the agar to ensure firm contact with the agar surface, and incubated at $37^{\circ} \mathrm{C}$ for $24 \mathrm{hrs}$. Following this the diameter of inhibition zone formed around each disk was measured using a black surface, reflected light and transparent ruler by lying it over the plates. The results were classified as sensitive, intermediate, and resistant according to the standardized table supplied by the manufacturer (CLSI 2008). E. coli ATCC 25922 type strains was used as a positive control.

\section{Data management and analysis}

The coded data was entered in MS Excel (Additional file 1) and then analyzed using SPSS version 15 (2006). The overall prevalence of $E$. coli O157: $\mathrm{H} 7$ in raw meat was determined using standard formula. The number of positive samples was divided by the total number of samples examined multiplied by 100. In addition to these, the prevalence in each meat type as well as at the selected retail shops and the abattoir was determined in the same way by dividing positive value with corresponding total examined samples. Difference among and between proportions of the groups with certain determinant factor was determined by chi-square $\left(x^{2}\right)$ test. A p-value $<0.05$ was considered indicative of a statistical significant difference.

\section{Description of raw data}

The following raw data are available with the online version of this paper with sample identification and corresponding results. The data file 1 (Additional file 1) is a table listing the type of meat (beef, sheep meat, goat meat) with their corresponding result; E. coli O157:H7 positive meat samples were represented with 1 whereas negative samples as 0 . Data file 2 (Additional file 1) contains raw data for antimicrobial susceptibility of $E$. coli O157: H7 isolated from beef, sheep meat and goat meat at an abattoir and in 48 selected raw meat retail shops in Addis Ababa.

\section{Results}

\section{Prevalence}

The overall prevalence of $E$. coli $\mathrm{O} 157: \mathrm{H} 7$ in three types of raw meat samples (beef, sheep and goat's meat) was $10.2 \%(39 / 384)$. Out of which $13.3 \%(17 / 128)$ were from beef, 9.4\% (12/128) from sheep meat and 7.8\% (10/128) from goat meat. The test statistics among three types of raw meat samples indicated that there was no statistical significance difference in prevalence rate $(\mathrm{p}>0.05)$ (Table 2).

Table 2. Prevalence of E. coli O157:H7 in abattoir and retail shops from different type of meat samples.

Among the food business operators, higher prevalence of E. coli $\mathrm{O} 157: \mathrm{H} 7$ was found in the retailer shops (14.6\%) than the abattoir (6.3\%) and there is significant difference in prevalence $(\mathrm{p}<0.05)$ (Table 2). However there was no statistically significant relationship difference in prevalence of $E$. coli $\mathrm{O} 157: \mathrm{H} 7$ isolated from the three types of meat both in the abattoir and in the retailer shops (Table 2).

\section{Antimicrobial susceptibility pattern}

The result of antimicrobial susceptibility test of $39 \mathrm{E}$. coli O157:H7 isolated from raw meat samples with 10 selected antimicrobial agents is shown in Table 3. The antimicrobial sensitivity test of E. coli O157:H7 isolated from different raw meat types revealed a varying degree of susceptibility to antimicrobial agents tested (Table 3).

Isolates recovered from sheep meat were found to be $40 \%$ to $80 \%$ susceptible to five antimicrobial agents tested except amoxicillin-clavulanic acid, ceftriaxone, cephalothin, chloramphenicol, and sulfamethoxazoletrimethoprim antimicrobial agents, which showed 100\% susceptibility (Table 3). Similarly, E. coli O157:H7 isolates from goat meat showed $100 \%$ susceptiblity to amikacin, ceftriaxone, chloramphenicol, sulfamethoxazole-trimethoprim and tetracycline. However, the remaining isolates showed a susceptibility ranging from $58.3 \%$ to $91.7 \%$. E. coli $\mathrm{O} 157: \mathrm{H7}$

Table 2 Prevalence of Escherichia coli 0157:H7 in abattoir and retail shops from different type of meat samples

\begin{tabular}{|c|c|c|c|c|c|}
\hline Food.business operators & Samples examined & № (\%) examined & № (\%) + ve & $x^{2}$ & P-value \\
\hline & Beef & 64(33.3) & $3(4.7)$ & & \\
\hline \multirow[t]{2}{*}{ Abattoir } & Sheep meat & 64(33.3) & $4(6.3)$ & 0.193 & 0.908 \\
\hline & Goat meat & 64(33.3) & $4(6.3)$ & & \\
\hline \multirow[t]{2}{*}{ Total } & & $192(50)^{*}$ & $11(5.7)^{*}$ & & \\
\hline & Beef & $64(33.3)$ & 14(21.9) & & \\
\hline \multirow[t]{2}{*}{ Retail shops } & Sheep meat & 64(33.3) & $8(10.9)$ & 4.348 & 0.114 \\
\hline & Goat meat & 64(33.3) & $6(9.4)$ & & \\
\hline Total & & $192(50)^{*}$ & $28(14.6)^{*}$ & & \\
\hline
\end{tabular}

+ ve $=\mathrm{E}$ coli contaminated; $\mathrm{p}$-value between food business operators (abattoir and retail shops $)^{*}=0.04$. 
recovered from beef showed a susceptibility to antibiotic ranging from $17.6 \%$ to $100 \%$.

Table 3. Antimicrobial susceptibility pattern of E. coli O157:H7 isolates $(n=39)$ to10 selected antimicrobial agents.

Out of 39 E. coli O157:H7 isolates subjected to antimicrobial susceptibility test a total of $23.1 \%$ were susceptible to all antimicrobials used; from these $55.5 \%$ isolates were from beef, $22.2 \%$ from sheep meat and goat meat each (Table 4).

Table 4. E. coli O157:H7 isolates susceptible to all antimicrobials.

Of the 39 E. coli O157:H7 isolates, 17.9\% were found to be resistant to three or more drugs tested of which $40 \%$ were recovered from beef samples (Table 5).

Table 5. Multidrug resistance (MDR) of E. coli O157:H7.

\section{Discussion}

Prevalence of E. coli 0157:H7

Raw meat and its products are commonly consumed in traditional Ethiopian diets, but E. coli $\mathrm{O} 157: \mathrm{H} 7$ is rarely studied compared to other countries. In the present study, E. coli O157:H7 was isolated from beef, sheep meat and goat meat at both the abattoir and the selected raw meat retailer shops at Addis Ababa. The overall prevalence of E. coli O157:H7 in the present study (10.2\%) was higher than the $4.2 \%$ reported in Modjo and Bishftu (Debre Zeit) (Hiko et al. 2008) in Ethiopia using immunomagnetic separation method which is much more sensitive than the plating method used in the present study.

The difference in the overall prevalence observed among the three types of meat samples in present study is high $(13.3 \%)$ in beef, but relatively similar between sheep meat (9.4\%) and goat meat (7.8\%). In contrast, the prevalence of E. coli $\mathrm{O} 157: \mathrm{H} 7$ in beef in this study was higher than the $8.8 \%$ prevalence reported by Abong (2008) in South Africa and Hajian et al. (2011) in Iran; and lower than $53 \%$ prevalence reported by Dahiru et al. (2008) in fresh beef meat in Nigeria.

In this study, the prevalence of $E$. coli $\mathrm{O} 157: \mathrm{H} 7$ in sheep meat $(9.4 \%)$ and goat meat $(7.8 \%)$ were higher than the previous study done by Hiko et al. (2008) in Ethiopia who reported a prevalence of $2.5 \%$ in sheep meat and $2 \%$ in goat meat. The presence of E. coli O157: H7 in sheep and goat meat might be due to contamination either from gastrointestinal content and/or skin (McEvoy et al. 2004).

With regard to meat source the higher prevalence of E. coli O157:H7 was found at the retailer shops (14.6\%) than the abattoir (5.7\%). The significant variation $(\mathrm{p}<$ 0.05 ) in prevalence (contamination) rate between the abattoir and the retailer shops could be due to the difference in hygienic practices, cooling and storage time used between the two. Moreover there could be risk of carcass contamination and cross and subsequent contamination, during transportation, environment, handling of meat at retailer shops.

The prevalence of $E$. coli O157:H7 was similar at the abattoir in beef, sheep meat and goat meat. There is no significant variation $(p>0.05)$ among the three type of raw meat samples. However difference in prevalence was observed among the three types of meat samples from raw meat from the retailer shops. The high prevalence was recorded in beef (21.9\%) than sheep meat (10.9\%) and goat meat $(9.4 \%)$. This could be due to the fact that bovine has been implicated as the principal reservoir of this pathogen as compared with other food animals (Fantelli and Stephan 2001).

Table 3 Antimicrobial susceptibility pattern of $E$. coli 0157:H7 isolates $(n=39)$ to10 selected antimicrobial agents

\begin{tabular}{|c|c|c|c|c|c|c|c|c|c|c|c|c|}
\hline \multirow{4}{*}{$\begin{array}{l}\text { Antimicrobial } \\
\text { used }\end{array}$} & \multicolumn{12}{|c|}{ Type of raw meat and $E$. coli $0157: \mathrm{H} 7$ isolates } \\
\hline & \multicolumn{3}{|c|}{ Beef $(n=17)$} & \multicolumn{3}{|c|}{ Sheep meat $(n=12)$} & \multicolumn{3}{|c|}{ Goat meat $(n=10)$} & \multicolumn{3}{|c|}{ Total $(n=39)$} \\
\hline & $\mathbf{S}$ & $\mathbf{I}$ & $\mathbf{R}$ & $\mathbf{S}$ & I & $\mathbf{R}$ & $\mathbf{S}$ & I & $\mathbf{R}$ & $\mathbf{S}$ & I & $\mathbf{R}$ \\
\hline & № (\%) & № $(\%)$ & № (\%) & № (\%) & № $(\%)$ & № (\%) & № (\%) & № $(\%)$ & № (\%) & № (\%) & № (\%) & № (\%) \\
\hline AK & $10(58.8)$ & $0(0)$ & $7(41.2)$ & 10(83.6) & $0(0)$ & $2(16.6)$ & $7(70)$ & $O(0)$ & $3(30)$ & $27(69.3)$ & $0(0)$ & 12(30.9) \\
\hline AMC & $17(100)$ & $0(0)$ & $0(0)$ & $9(75)$ & $0(0)$ & $3(25)$ & 10(100) & $0(0)$ & $0(0)$ & $36(92.3)$ & $0(0)$ & $3(7.7)$ \\
\hline $\mathrm{CRO}$ & $17(100)$ & $0(0)$ & $0(0)$ & $12(100)$ & $0(0)$ & $0(0)$ & $6(60)$ & $4(40)$ & $0(0)$ & $39(100)$ & $0(0)$ & $0(0)$ \\
\hline KF & 15(88.2) & $2(11.8)$ & $0(0)$ & $7(58.3)$ & $0(0)$ & $5(41.7)$ & $10(100)$ & $0(0)$ & $0(0)$ & $32(82.1)$ & $2(5.1)$ & $5(12.8)$ \\
\hline C & 17(100) & $0(0)$ & $0(0)$ & $12(100)$ & $0(0)$ & $0(0)$ & $10(100)$ & $0(0)$ & $0(0)$ & $39(100)$ & $0(0)$ & $0(0)$ \\
\hline CIP & 13(76.5) & $0(0)$ & $4(23.5)$ & $9(75)$ & $0(0)$ & $3(25)$ & $6(60)$ & $4(40)$ & $0(0)$ & $28(71.8)$ & $4(10.3)$ & $7(17.9)$ \\
\hline NA & $17(100)$ & $0(0)$ & $0(0)$ & 10(83.6) & $2(16.4)$ & $0(0)$ & $4(40)$ & $4(40)$ & $2(20)$ & $31(79.5)$ & $6(15.4)$ & $2(5.1)$ \\
\hline S & $4(23.5)$ & $7(4.1)$ & $6(35.3)$ & $11(91.6)$ & $0(0)$ & $1(8.4)$ & $4(40)$ & $0(0)$ & $6(60)$ & 19(48.7) & $7(17.9)$ & 13(33.4) \\
\hline TE & $17(100)$ & $0(0)$ & $0(0)$ & $12(100)$ & $0(0)$ & $0(0)$ & $8(80)$ & $2(20)$ & $2(20)$ & $37(94.9)$ & $0(0)$ & $2(5.1)$ \\
\hline SXT & $17(100)$ & $0(0)$ & $0(0)$ & $12(100)$ & $0(0)$ & $0(0)$ & $10(100)$ & $0(0)$ & $0(0)$ & $39(100)$ & $0(0)$ & $0(0)$ \\
\hline
\end{tabular}

See Table 2 for key abbreviations; $S=$ Sensitive, I = Intermediate, $R=$ Resistant. 


$\begin{aligned} & \text { Table } 4 \text { E. coli } \\
& \text { antimicrobials }\end{aligned}$
\begin{tabular}{|lll}
\hline $\begin{array}{l}\text { Type of raw } \\
\text { meat }\end{array}$ & $\begin{array}{l}\text { № of isolates } \\
\text { tested }\end{array}$ & $\begin{array}{l}\text { № (\%) of isolates susceptible } \\
\text { to all antimicrobials }\end{array}$ \\
\hline Beef & 17 & $5(55.5)$ \\
Sheep meat & 12 & $2(22.2)$ \\
Goat meat & 10 & $2(22.2)$ \\
Total & 39 & $9(23.1)$ \\
\hline
\end{tabular}

\section{Antimicrobial susceptibility pattern of E. coli 0157:H7}

The use of antibiotics in the treatment of infection with E. coli $\mathrm{O} 157: \mathrm{H} 7$ is controversial, since antimicrobial therapy may increase the risk of development of HUS (Hemolytic uremic syndromes) (Mølbak et al. 2002). Although some studies do not advice antibiotic treatment for infections caused by such bacteria (Wong et al. 2000), others suggest that disease progression may be prevented by administrating antibiotic at early stage of infection (Shiomi et al. 1999). Thus, for better response, antimicrobial susceptibility test is necessary (Quinn et al. 2002). Hence, on the basis of this necessity, antimicrobial susceptibility test was conducted on the isolates recovered from raw meat.

Antimicrobial resistance of $E$. coli $\mathrm{O} 157: \mathrm{H} 7$ isolates from animal and human sources have been reported in Ethiopia by Hiko et al. (2008). In the present study $E$. coli $\mathrm{O} 157: \mathrm{H} 7$ showed resistance to seven antimicrobials which varied from $5.1 \%$ to $33.4 \%$ except to ceftriaxone, chloramphenicol, and sulfamethoxazole-trimethoprim to which $100 \%$ susceptibility was noticed. The $100 \%$ susceptibility of all the isolates to chloramphenicol, ceftriaxone and sulfamethoxazole-trimethoprim is consistent with the findings of Rangel and Marin (2009) and Rahimi and Nayebpour (2012). Most of these antimicrobials are not commonly used in Ethiopia in the treatment of animals that served as a source of meat. Moreover, the susceptibility might have contributed to the effectiveness of these antimicrobials mostly against Gram negative bacteria like those of the family of Enterobacteriaceae to which E. coli O157:H7 belongs.

Table 5 Multidrug resistance (MDR) of E. coli 0157:H7

\begin{tabular}{|c|c|c|c|c|}
\hline \multirow{2}{*}{$\begin{array}{l}\text { Type of drugs } \\
\text { registered } \\
\text { as MDR }\end{array}$} & \multicolumn{3}{|c|}{ Source of resistant isolates } & \multirow{2}{*}{$\begin{array}{l}\text { Total } \\
\text { № (\%) }\end{array}$} \\
\hline & Beef (№) & $\begin{array}{l}\text { Sheep } \\
\text { meat (№) }\end{array}$ & $\begin{array}{l}\text { Goat } \\
\text { meat (№) }\end{array}$ & \\
\hline$\overline{A K}, \mathrm{~S}, \mathrm{TE}$ & - & - & 2 & $2(28.6)$ \\
\hline$A K, C I P, S$ & 2 & - & - & $2(28.6)$ \\
\hline$A M C, C I P, S$ & 1 & - & - & $1(14.3)$ \\
\hline $\mathrm{AK}, \mathrm{KF}, \mathrm{CIP}, \mathrm{S}$ & 1 & - & - & $1(14.3)$ \\
\hline$A K, A M C, K F, S$ & - & 1 & - & $1(14.3)$ \\
\hline Total MDR № (\%) & $4(57.1)$ & $1(14.3)$ & $2(28.6)$ & $7(17.9)$ \\
\hline
\end{tabular}

See Table 2 for key abbreviations; $S=$ Sensitive, $\mathrm{I}=$ Intermediate, $\mathrm{R}=$ Resistant.
The high resistance to streptomycin in this study is in agreement with Hiko et al. (2008) who reported antimicrobial resistance to $E$. coli $\mathrm{O} 157: \mathrm{H} 7$ isolates from raw meat samples to some of above mentioned antimicrobials especially to streptomycin. The significantly high level of resistance to these antimicrobials was probably an indication of their extensive usage in the veterinary sector for therapeutic and prophylactic purpose both for E. coli and other infections.

Antimicrobial resistance emerges from the use of antimicrobials in animals and human, and the subsequent transfer of resistance genes and bacteria among animals, humans and animal products and the environment (Scott et al. 2002). The shedding of the resistant bacteria into the environment by cattle may lead to a widespread dissemination of antibiotic resistant genes to the resident bacteria in the environment (Callaway et al. 2003; Mashood, et al. 2006). Evidence has been found which indicates that resistant strains of pathogens can be transmitted to humans through food (Oosterom 1991; Khachatourians 1998). Antibiotic resistance among foodborne pathogens may create an increased burden to human health through: it's potential to reach humans, increasing the risk of acquiring an infection in human who taking prior antibiotic treatment, limiting illness treatment options and may be by developing increased virulence (IFT 2006).

Recently, multidrug resistant (MDR) phenotypes have been spread widely among Gram negative bacteria (Ahemed et al. 2006). MDR was observed among amikacin, amoxycillin-clavulanic acid, cephalothin, ciprofloxacin, streptomycin and tetracycline antimicrobials in this study. This is in agreement with the findings by other researchers, who reported multidrug resistance among E. coli O157:H7 isolates (Kim et al., 1994; Schroeder et al., 2002). From the above mentioned antimicrobials streptomycin is found in all MDR E. coli O157:H7 isolates. This finding was supported by Hiko et al. (2008).

Increased sensitivity of antimicrobial resistant $E$. coli O157 to environmental or food processing related stresses (acid and heat) have been reported by different authors. Duffy et al. (2006) reported that MDR E. coli O157:H7 (resistant to 10 antibiotics) when subjected to food stresses (acid and heat) was found to act very differently to the unstressed antibiotic sensitive and antibiotic resistant VTEC strains. All VTEC strains tested were found to survive for approximately 30 days in orange juice at $\mathrm{pH} 4.4$ and 25 days in yoghurt at $\mathrm{pH} 4.2$. The exception was the MDR E. coli O157:H7 isolate which was found to have died off significantly faster $(\mathrm{P}<0.05)$ in both media, than in the other strains tested. Thermal inactivation studies also showed the MDR strain to be significantly more heat sensitive (D55 value $=1.71 \mathrm{~min}$ ) than all other VTEC strains examined (Clavero et al. 1998; Byrne et al. 2002; Huang and Juneja 2003). 


\section{Conclusions}

One of the most significant food-borne pathogens that have gained increased attention in recent years is $E$. coli O157:H7. In this study, isolation of E. coli O157:H7 from raw beef, sheep meat and goat meat and the existence of resistant isolates highlight the potential threat to public health. Hence implementation of E. coli O157:H7 prevention and control strategies from farm production to consumption of meat and meat products are crucial.

\section{Additional file}

\section{Additional file 1: Raw Data for Escherichia coli 0157:H7 in Raw}

Meat in Addis and Antimicrobial Susceptibility.

\section{Competing interests}

The authors declare that they have no competing interests.

\section{Authors' contributions}

TB: conception and design, acquisition of data, analysis and interpretation of data, drafting the manuscript; GZ: conception and design, acquisition of data; drafting manuscript; GT: conception and design, acquisition of data laboratory work; AF: acquisition of data, analysis and interpretation of data, drafting the manuscript; KZ: participated in its design, analysis and interpretation of data, revising it critically for important intellectual content. All authors read and approved the final manuscript.

\section{Acknowledgements}

The authors are very grateful to Institute of Biodiversity Conservation Microbial Genetic Resources Centre and College of Veterinary Medicine and Agriculture, Addis Ababa University for their financial and laboratory facility provision for running this project.

\section{Author details}

${ }^{1}$ College of Veterinary Medicine and Agriculture, Addis Ababa University, P.O. Box 34, Bishftu, Ethiopia. ${ }^{2}$ Institute of Biodiversity Conservation, Microbial Genetic Resources Centre, P.O. Box 30726, Addis Ababa, Ethiopia. ${ }^{3}$ College of Veterinary Medicine, Samara University, P.O. Box 132, Samara, Ethiopia.

Received: 8 August 2013 Accepted: 4 June 2014

Published online: 29 July 2014

\section{References}

Abdalla MA, Siham E, Suliman YYH, Alian A (2009) Microbial Contamination of sheep carcasses at El Kadero slaughter house Khartoum State, Sudan. J Vet Sci 48:1-2

Abong BO (2008) Prevalence of Escherichia coli O157:H7 in water and meat and meat products and vegetables sold in the Eastern Cape Province of South Africa and its impact on the diarrheic conditions of HIV/AIDS patients. Dissertation. The University of Fort Hare. Cape Town, South Africa, p 261

Acha PN, Szyfres B (2001) Colibacilosis. In: Zoonoses and Communicable Diseases Common to Man and Animals, 3rd edn. pp 90, Washington, D.C, p 106

Ahemed A, Li J, Shiloach Y, Robbins JB, Szu SC (2006) Safety and immunogenicity of Escherichia coli 0157 O-specific polysaccharide conjugate vaccine in 2-5 year old children. J Infect Dis 193(4):515-521

Bacon RT, Belk KE, Sofos JN, Clayton RP, Reagan JO, Smith GC (2000) Microbial populations on animal hides and beef carcasses at different stages of slaughter in plants employing multiple sequential interventions for decontamination. J Food Prot 63(8):1080-1086

BiOLOG User Guide (2008) Data Collection Software Identification System User Guide. Biolog, Inc., Hayward, CA

Byrne CM, Bolton DJ, Sheridan JJ, Blair IS, McDowell DA (2002) The effect of commercial production and product formulation stresses on the heat resistance of Escherichia coli 0157: H7 (NCTC 12900) in beef burgers. Int J Food Microbiol 79:183-192

Callaway RT, Anderson CR, Elder RO, Edrington ST, Genovese JK, Bischoff MK, Poole LT, Jung SY, Harvey BR, Nisbet JD (2003) Preslaughter Intervention
Strategies to Reduce Food-Borne Pathogens in Food Animals. J Anim Sci $81: 2$

Chapman PA, Cerda'n Malo AT, Ellin M, Ashton R, Harkin M (2001) Escherichia coli 0157 in cattle and sheep at slaughter, on beef and lamb carcasses and in raw beef and lamb products in South Yorkshire,UK. Int J Food Microbiol 64 (1-2):139-150

Clavero MRS, Beuchat LR, Doyle MP (1998) Thermal Inactivation of Escherichia coli 0157: H7 isolated from ground beef and bovine feces, and suitability of media for enumeration. J Food Prot 61:285-289

CLSI (2008) Performance Standards for Antimicrobial Disk and Dilution Susceptibility Tests for Bacterial Isolated from Animals, 3rd edn. CLSI, Wayne, PA, USA, M31-A-3, 28

Cornick NA, Booher SL, Casey TA, Moon HW (2000) Persistent colonization of sheep by Escherichia coli 0157:H7 and other E. coli pathotypes. Appl Environ Microbiol 66(11):4926-4934

Dahiru M, Uraih N, Enabulele SA, Shamsudeen U (2008) Prevalence of Escherichia Coli 0157:H7 in fresh and roasted beef in Kano City. Nigeria Bayero J Pure Appl Sci 1:39-42

Doyle MP, Institute of Food Technologists (IFT) (2006) Expert Panel Report Summary on Dealing with antimicrobial resistance. Institute of Food Technologists. pp 24

Duffy G, Walsh C, Blair IS, McDowell DA (2006) Survival of antibiotic resistant and antibiotic sensitive strains of E. coli $\mathrm{O} 157$ and E. coli $\mathrm{O} 26$ in food matrices. Int J Food Microbiol 109:179-186

Fantelli K, Stephan R (2001) Prevalence and characteristics of Shigatoxinproducing Escherichia coli and Listeria monocytogenes strains isolated from minces meat in Switzerland. Int J Food Microbiol 70:63-69

Hajian S, Rahimi E, Mommtaz H (2011) A 3-year study of Escherichia coli 0157:H7 in cattle, camel, sheep, goat, chicken and beef minced meat in Proceedings of the International Conference on Food Engineering and Biotechnology (IPCBEE '11). IACSIT Press, Singapoore

Hiko A, Asrat D, Zewde G (2008) Occurrence of Escherichia coli 0157:H7 in retail raw meat products in Ethiopia. J Infect Dev Ctries 2(5):389-393

Huang L, Juneja VK (2003) Thermal inactivation of Escherichia coli O157: H7 in ground beef supplemented with sodium lactate. J Food Prot 66:664-667

Institute of Food Technologists (IFT) (2003) Expert Report on Emerging Microbiological Food Safety Issues. In: Implications for Control in the 21st Century. S. Lowry/Univ. Ulster/Stone, Institute of Food Technologists, pp 1-32

International Organization for Standardization 17604 (ISO 17604) (2005) Microbiology of Food Animal, Feeding Stuffs-Carcass Sampling for Microbiological Analysis., pp pp 1-pp 12

Kaper JB, Nataro JP, Mobley HLT (2004) Pathogenic Escherichia coli. Nat Rev Microbiol 2:123-140

Khachatourians G (1998) Agricultural Use of Antibiotics and the Evolution and Transfer of Antibiotic Resistant Bacteria. CMAJ 159:1129-1136

Kim H, Samadpour M, Grimm L, Clausen C, Besser T, Baylor M, Kobayashi J, Neill LM, Schoenknecht F, Tarr P (1994) Characteristics of Antibiotic-Resistant Escherichia coli O157:H7 in Washington State, 1984-1991. J Infect Dis 170:1606-1609

Mashood AR, Minga U, Machugun RK (2006) Current Epidemiologic Status of Enterohaemorrhagic Escherichia coli 0157:H7 in Africa. Chin Med J 119 (3):217-222

McEvoy JM, Sheridan JJ, McDowell DA (2004) Major pathogens associated with the processing of beef. In: Collins JD (ed) Smulders FJM. Wageningen Academic Publishers, Safety Assurance during Food Processing, pp 57-80

McEwen SA, Fedorka-Cray PJ (2002) Antimicrobial Use and Resistance in Animals. Clin Infect Dis 34(Suppl3):S93-S106

Mead PS, Griffin PM (1998) Escherichia coli O157:H7. Lancet 352(9135):1207-1212

Meng J, Doyle MP (1998) Microbiology of shiga toxin producing Escherichia coli in foods. In: Kaper JB, O'Brien AD (eds) Escherichia coli O157:H7 and other shiga-toxin producing E. coli strains. American Society for Microbiology, Washington, DC, pp pp 92-pp 108

Mølbak K, Mead PS, Griffin PM (2002) Antimicrobial therapy in patients with Escherichia coli O157:H7 infection. JAMA 288:1014-1016

Oosterom J (1991) Epidemiological Studies and Proposed Preventive Measures in the Fight Against Human Salmonellosis. Int J Food Microbiol 12:41-51

Pal M (2007) Zoonoses, 2nd edn. Satyam Publishers, Jaipur, India, pp 104-105

Quinn P, Carter M, Markey B, Carter G (2002) Clinical Veterinary Microbiology. Enterobacteriaceae. Wolfe Pub. Spain, In, pp 209-236 
Rahimi E, Nayebpour F (2012) Antimicrobial resistance of Escherichia coli O157: H7/NM isolated from feces of ruminant animals in Iran. JCAB 6:104-108. doi:10.5897/JCAB11.082

Rangel PM, Marin JM (2009) Antimicrobial resistance in brazilian isolates of Shiga toxin-encoding Escherichia coli from cows with mastitis. ARS VETERINARIA, Jaboticabal, SP 25:018-023

Schroeder CM, Zhao C, DebRoy C, Torcolini J, Zhao S, White GD, Wagner DD, McDermott FP, Walker DR, Meng J (2002) Antimicrobial Resistance of Escherichia coli O157:H7 Isolated from Humans, Cattle, Swine, and Food. J Appl Environ Microbiol 68:576-581

Shiomi M, Togawa M, Fujita K, Murata R (1999) Effect of early oral fluroquinones in hemoragic colitis do to Escherichia coli O157:H7. Pediatr Int 41(2):228-232

SPSS (2006) Inc SPSS for windows (version 15.0). SPSS Inc., Chicago, Illinois, USA, http://www.hist.umn.edu/ ruggles/hist5011/SPSSBriefGuide150.pdf Accessed 7 July 2014

The Center for Food Security and Public Health (CFSPH) (2009) Enterohemorrhagic Escherichia coli (EHEC) infections. http://www.cfsph. iastate.edu/Factsheets/pdfs/e_coli.pdf Accessed 12 Oct 2013

Vernozy-Rozand C (1999) Verotoxin-producing Escherichia coli (VTEC) and Escherichia coli O157:H7 in medicine and food industry. Ann Biol Clin 57:507-515

Wong CS, Jelacic S, Habeeb RL, Watkins SL, Tarr PI (2000) The risk of hemoragic uramic syndrome after antibiotic treatment of Escherichia coli 0157:H7 infections. N Engl J Med 342:1930-1936

doi:10.1186/s40550-014-0004-9

Cite this article as: Bekele et al.: Escherichia coli 0157:H7 in Raw Meat in Addis Ababa, Ethiopia: Prevalence at an Abattoir and Retailers and Antimicrobial Susceptibility. International Journal of Food Contamination 2014 1:4.

\section{Submit your manuscript to a SpringerOpen ${ }^{\circ}$ journal and benefit from:}

- Convenient online submission

- Rigorous peer review

- Immediate publication on acceptance

- Open access: articles freely available online

- High visibility within the field

- Retaining the copyright to your article 